\title{
Enhancing Practicum Supervision with Asynchronous and Synchronous Technologies
}

\author{
Yiong Hwee Teo ${ }^{1, *}$, Sue McNamara ${ }^{2}$, Geoff Romeo ${ }^{2}$, Donna Gronn ${ }^{2}$ \\ ${ }^{1}$ National Institute of Education, Nanyang Walk, Singapore \\ ${ }^{2}$ Australian Catholic University, Australia
}

Copyright (c) 2015 Horizon Research Publishing All rights reserved.

\begin{abstract}
Three video/web conferencing technologies (Pocket Camcorder, Skype, Adobe Connect) were used in regional schools in Australia to determine whether the technologies are appropriate for the needs of the university supervisor, trainee teachers and supervising teachers with regard to practicum teaching placements. Findings revealed that Pocket Camcorders gave good video quality and were very portable but had constraints of limited field of vision and poor sound quality. Skype and Adobe Connect are cross platform, offered good audio and video resolution and were the most appropriate technologies. However supervisors and users need to be aware of limitations. Implications are drawn for professional experience and pedagogy.
\end{abstract}

Keywords Web Conferencing, Pre-service Teacher, Practicum, Field Experience, Remote Observation

\section{Introduction}

Field experience or teaching practicum is an important component of pre-service teacher (PST) education in preparing future teachers for the complexity and rigors of profession. However it remains a challenge to locate and place PSTs in appropriate field settings. It is impossible to guarantee that they will have the opportunity to be supervised by talented teachers and faculty members. Other challenges include: securing placements in a specific area for those undertaking courses to become high school teachers, finding appropriate supervising teachers to mentor PSTs, issues concerning scheduling problems and disrupting the classroom environment [1]. Faculty demands for research output, teaching workload, the need to keep costs down and the need to supervise a large number of PSTs also mean that the university supervisor is not always available, or willing, to undertake supervision. The challenge is compounded when supervisors need to travel long distances for on-site supervision in rural and remote regions.

Technology such as video conferencing may have the potential to address some of these challenges. Video conferencing has been widely used in educational settings since the mid-1980s. Much of the literature on the use of video conferencing for practicum supervision is US-based and involved proprietary and expensive equipment such as the Polycom View station system [2]. Nowadays video conferencing via the web or web conferencing is more often used. The purpose of this study was to field-test several asynchronous and synchronous web conferencing technologies in schools to determine whether the technologies are appropriate for the needs of the university supervisor, the PST and the supervising teacher in the school. Synchronous technologies in this context mean technologies supporting learning at same place and time and asynchronous technologies means technologies supporting learning at different place and different time. This research was important in updating research on the use of three technologies for practicum supervision from an Australian perspective and was designed to explore three research questions:

1. What are the strengths and limitations of these technologies?

2. What training and support is required in order to use these technologies effectively?

3. What is the potential of these technologies for professional experience pedagogy and beyond?

This paper reviews the literature on observation and feedback concerning PST conferencing during practice teaching supervision. It then describes the participants and the context in the study. A discussion of the methodology follows. Finally the findings on the use of the three technologies are reported and conclusions and implications are drawn.

\section{Literature Review}

Two of the most important tasks university supervisors and supervising teachers need to undertake in PST practicum supervision are observation of practice teaching and providing feedback to the PSTs. Insufficient observation and feedback at the beginning of the practicum 
may lead the PST to inappropriate practice. The literature reviewed the use of video conferencing for practicum supervision in three areas: observation and feedback during teaching, observation during teaching/feedback after teaching, and observation and feedback after teaching.

\subsection{Observation /Feedback during Teaching}

There is literature discussing the observation of PSTs during their teaching practicum, but also of PSTs observing experienced teachers. In the latter, the university supervisor guides PSTs in their observation of a live lesson given by an experienced teacher. This was transmitted via video conferencing to the university site [1, 3-5]. The strength of this method lies in the shared observation of a common teaching episode where the supervisor can manage the observational experience by giving feedback to a group of PSTs on what to observe and how to interpret the classroom dynamics. An advantage is that children in the classroom are oblivious to, and undisturbed by, the observation thus maintaining natural classroom behavior [3]. To be able to observe different kinds of classrooms and activities without the need to be placed in different schools is a value-added attribute [2].

University supervisors can observe the teaching by PSTs and give immediate feedback via a 'bug-in-ear' technology where the trainee teacher hears the supervisor's feedback using an earpiece device [4]. Using immediate feedback to change teaching and instructional techniques through corrective feedback while the lesson is in progress is reported by Scheeler and Lee ([5] to be an efficient and effective way of changing teacher behavior. However, Scheeler, et al. cautioned that providing immediate feedback during lessons may be disruptive to the flow of the lesson and distracting to the PST.

\subsection{Observation during/Feedback after Teaching}

For personal preference, you may import styles into your own manuscript. The process is divided into 4 steps: Most of the literature falls into this category where the supervisor based at the university observes, via conferencing, the pre-service teacher teaching at a school and feedback is given after the lesson. Effective performance feedback can then be given close to the actual teaching when recall of the episode is still fresh. Bolton [6] reported nearly all of her PST participants felt that non-invasive observation at a distance is far less intrusive and distracting than a physical presence in the classroom. Non-invasive observation can also allow multiple PSTs to observe and monitor a class through conferencing off-site without interfering in the actions of the students [7], thus giving PSTs more opportunities to observe expert teachers implement educationally sound pedagogical practice and have meaningful dialogue with the classroom teacher [8].

\subsection{Observation after/Feedback after Teaching}

Synchronous web conferencing is not possible when an Internet connection is unavailable. This category involves the supervisor observing a recording of the teaching and giving feedback after or during the video observation. Cappizi, Wehby and Sandmel [9] reported that a debriefing consultation using video recorded lessons was effective in increasing the number of lesson components and amount of behavior-specific praise delivered during instruction for all participants in subsequent lessons. In a comparison of the quality of reflection, where the supervisor and trainee teacher viewed a recorded lesson during debriefing and traditional in-class observation based debriefing, Sewall [10] found that the former promoted more reflective comments both in quantity and quality. Watching themselves in action is also a more objective way of reflection compared to receiving feedback from a third person thus enabling reflective practice [11], a definite strength of video-recorded asynchronous mode. This study reports the use of both asynchronous video recording (Pocket Camcorders) and synchronous web conferencing (Skype and Adobe Connect) technologies.

\section{Data Collection and Analysis}

The data collection instruments included observations of lessons, accompanied by a PST survey, supervisor survey, audio recording of focus group interview with principals, technicians and teachers, individual PST interviews, video of classroom observations, and field notes from participants.

The PST survey sought participants' feedback on strengths and limitations of using the technology and the level of training and support required to use the technology effectively. The survey was emailed to PSTs immediately after the observed teaching episodes. The quantitative questions were Likert-scale type items measuring the perceived benefits and limitations of web conferencing and whether the PST needed technical help to operate the technology. The open-ended items asked for comments on the use of functions connected with the technology and any other remarks. The supervisor survey seek comments on the strengths and limitations of the technology, the supervisor's preference for using the technology compared to on-site observation and asked about the PST's planning, preparation and in-class skills. The focus group interview with the principal, technician and a co-operating teacher from two of the primary schools was to explore and probe participants' viewpoints in an open but structured environment. Each interview lasted for about 45 minutes and was audio taped to assist in accurately capturing all responses. Verbatim transcriptions from the audio recordings were then made. The interview focused on issues such as pedagogy, ethical requirements such as obtaining parental permission for their children to participate in an internet video based activity, and the potential and limitations of using a different method of practicum supervision. The PST interview sought views on the use of microphone, webcam positioning, whether the use 
of this method influenced PST teaching in any way and the training and support that was required. All the interviews also served to obtain in-depth views on some of the items in the surveys and offered a source for triangulation.

\section{Findings}

The findings are reported according to the type of technology - pocket camcorder and web conferencing (Skype and Adobe Connect).

\subsection{The Pocket Camcorder Trials}

The Pocket Camcorder has emerged in recent years as a new class of digital video camera known for its small size, portability and low price (most are less than $\$ 200$ ). Pocket camcorders do not have any broadcasting capability. They are not designed for synchronous conferencing. They can however be used asynchronously to record events for viewing later. Two pocket camcorders, the Flip Camera and Sony Bloggie were trialed in both secondary and primary schools. As the two camcorders were very similar in functions, only the Flip Camera will be discussed in this section due to space constraints.

\subsubsection{What are the strengths and limitations of the Pocket Camcorder technology?}

The strengths of the Flip camcorder are that it is inexpensive, portable, simple to use, and capable of capturing HD quality video in MPEG 4 (mp4) format of up to 60 minutes. The user just turns the power on, presses the record button and video capture begins. To transfer the video footage, the user simply flips out the USB arm and connects it to the computer to launch the pre-loaded FlipShare software. Captured footage looked sharp and the colors were sufficiently vibrant. Subjects in poorly lit environments appeared sufficiently clear.

The Flip camcorder however had many limitations. Its fixed focal lens with no zooming meant that the camera had to be placed at the back of the classroom in order to capture both teacher and students in action due to the narrow angle of view. The camera was prone to camera shake and needed to be mounted on a tripod which was the case for this study. The omni-directional microphone could not discern individual voices when the whole class was involved in conversations resulting in poor sound quality. Another limitation was the sixty minutes (4 GB) limit of stored footage. Users can use the FlipShare software to upload video files online or use other free sharing sites (e.g. Dropbox). A paid subscription would allow for uploading multiple large files. It is a good practice to ensure that video file size is not too large as this would cause uploading and downloading issues when bandwidth is a problem. For this study, FlipShare was not used. PSTs returned the Flip Cameras after teaching and supervisors transferred the recordings onto their computers directly.

\subsubsection{What training and support is required in order to use this technology effectively?}

To share the footage with their supervisors, PSTs need to possess basic computer knowledge of: how to turn on and operate the camera; how to transfer video footage to the computer using the built-in software, or via file transfer; knowledge of video file format and size; how to use the FlipShare or Bloggie software for sharing; and how to register and login to a sharing site (eg. Dropbox) and upload footage to the sharing site. While it was not difficult to operate these cameras, it would be good if PSTs were able to experience using the camera before practicum starts. As an asynchronous transmission solution, the Flip Camera and Sony Bloggie do not depend on the school's network to broadcast the video during teaching. This has the advantage of not loading stress on PSTs to ensure connectivity before the start of the lesson.

\subsection{The Skype and Adobe Connect Trials}

Due to the similarity of these two web conferencing applications, the strengths and limitations will be discussed together and any differences highlighted.

\subsubsection{What are the strengths and limitations of web conferencing technology?}

\section{The Skype conferencing interface}

Skype is a web conferencing program using voice over Internet protocol (VOIP) technology. It is multi-lingual, cross platform and the basic version is free to download. The free version (trialed in this study) allows multiple users in an audio conference, but only one connection when using video. For slow connections, the video can be intermittent but audio calls are generally good quality. For education, Skype can be used to teach groups of people, either all connected separately to the presenter, or in a group with the computer connected to a projector. As Skype sessions were completed with a supervisor using an Apple computer in this study, the sessions were recorded using a paid app, Call Recorder (http://www.ecamm.com/mac/callrecorder/). Unlike other web conferencing software such as Elluminate and Adobe Connect, Skype lacks webinar features like white boards and polls. Text chat and screen sharing are however present in Skype's free version. While Skype lacks advanced features, its simplicity of use and low cost makes it a popular and accessible tool to less technologically experienced users.

\section{The Adobe Connect conferencing interface}

Adobe Connect is a flash-based webinar conferencing software used for training, marketing and online teaching. To initiate the conference, the host emails a weblink, and the participants join the meeting via the link. The videoconference host can assign others a status of host, presenter or participant. The web conference can also be 
recorded for post-viewing. Many universities have a license for a web conferencing program such as Adobe Connect for internal use. This can easily be extended to use in the practicum as PSTs in any school system can be invited to participate in a web-conference. The study found several features in Adobe Connect to be useful for practicum supervision. First the moderator can enlarge or shift positions of any of the multiple screens (video, chat, computer screen) to have a larger picture of specific sections of the lesson. Secondly, the use of the chat screen for supervisors to discuss the lesson with each other without disturbing the lesson. In one lesson, there were five supervisors logged in to view the PST in action. They were all able to view and hear the lesson and the chat area enabled them to exchange ideas and thoughts of the teaching episode. It would be impractical and disruptive to have five supervisors in a face-to-face supervision.

The researchers and supervisors were disappointed with the limited angle of view of the built-in camera on the laptop and the difficulty in capturing student voices. This comment from one supervisor is indicative of everyone's observations:

The peripheral activity is absent and there is no option for observation of student work. There is also difficulty in hearing students. There is a need to be able to manipulate the view of the camera. Whilst the span is appropriate for some activities, at other times there was a need to focus in some areas and expand for others. Remote controlling of the camera during the lesson would add this much needed element.

The video and audio quality of web conferencing applications depended on the webcam and microphone used. To enable a higher quality video capture, an external webcam (Logitech C905) was procured. While the external webcam gave a wider and clearer view, both were still not sufficiently wide angled to capture the entire classroom. Placing the webcam high and to the front and side of the classroom was generally the best compromise.

Audio quality was dependent on the microphone used and the distance between the microphone and the speaker. The PSTs did not use the built-in microphone of their laptops or the microphone built into the Logitech webcam. Instead, a Sony (ECMAW3) Bluetooth wireless external microphone was chosen. The PST clipped the microphone on their clothing and the receiver, which received the signal via Bluetooth, was connected to the laptop via the computer audio jack. The microphone picked up the teacher's voice clearly and the wireless transmission was unimpeded by physical obstruction. The sound pickup of students' responses in the background ranged from 'acceptable' to 'inadequate' depending on the distance of the clip-on microphone to the students. One supervisor noted some limitations of a Skype lesson.

Quality of student audio and lack of close ups; would have been pleased to see more of what individuals on the floor and at desks were doing, and also the audio of what they were saying.

The peripheral activity is absent and there is no option for observation of student work. There is also difficulty in hearing students. There is a need to be able to manipulate the view of the camera. Whilst the span is appropriate for some activities, at other times there was a need to focus. Fast broadband connection in the school was an important factor to ensure the transmission of the video capture was smooth and not pixilated. Skype delivered good to very good resolution, with Adobe Connect being better. This may be due to the dedicated bandwidth provided by the university network for Adobe Connect compared to Skype which has to contend for bandwidth with other traffic on the Internet.

\subsubsection{What training and support is required in order to use this technology effectively?}

Compared with Pocket Camcorders, PSTs needed more computer skills to work with web conferencing technologies. These included: going into the Options menu to pre-test the webcam and microphone settings; adjusting the playback and recording level setting of the soundcard driver; trying different webcam placements for optimum visual; testing the external microphone and replacing depleted batteries; and working the Skype or Adobe Connect software. The PSTs found it easy to use the conferencing software although the Adobe Connect interface is slightly more complex than Skype. The PSTs were in their early twenties and it may have taken more time for less experienced technology users. University supervisors need similar technology skills to those described above for PSTs except that they do not have to deal with webcam and microphone placements in the classroom. Table 1 compares the strengths and limitations of Pocket Camcorder, Skype and an in-person supervisor.

\section{Discussion and Conclusions}

Overall, feedback from university supervisors, trainee teachers and supervising teachers has shown that Skype and Adobe Connect are the favored options with regard to remote practice teaching supervision. They are cross platform, capable of synchronous and asynchronous broadcast of classroom teaching, and offer good audio and video resolution. The caveat is that they require good broadband 
Table 1. Comparison of Pocket Camcorder, Skype and In-person Visit

\begin{tabular}{|c|c|c|c|}
\hline & Pocket Camcorder & Skype/Adobe Connect & In-person Visit \\
\hline Cost & $\begin{array}{l}\text { S Most are affordable at below } \\
\$ 200\end{array}$ & $\begin{array}{l}\text { S Free for basic version; } \\
\text { subscription for AC }\end{array}$ & $\begin{array}{l}\mathbf{L} \text { Time spent and cost of } \\
\text { travelling to and from school }\end{array}$ \\
\hline Audio, Video & $\begin{array}{l}\text { S Very Good quality audio \& } \\
\text { video possible } \\
\text { L Angle of view is limited }\end{array}$ & $\begin{array}{c}\text { S Good quality audio \& video } \\
\text { possible } \\
\text { L Audio \& video quality } \\
\text { dependent on microphone and } \\
\text { webcam used and their placement }\end{array}$ & $\begin{array}{l}\text { S Presence and good wide angle } \\
\text { view of classroom dynamics } \\
\mathbf{L} \text { Difficult to pick up discussion } \\
\text { of small groups if supervisor is } \\
\text { seated at back of classroom }\end{array}$ \\
\hline Synchronous & $\begin{array}{c}\text { L Not possible for real-time } \\
\text { viewing and feedback of teaching }\end{array}$ & $\begin{array}{l}\text { S Real-time viewing of teaching } \\
\text { event by supervisor } \\
\text { S Feedback can be given } \\
\text { immediately after lesson } \\
\text { L Only 1 supervisor can view } \\
\text { event unless paid subscription }\end{array}$ & $\begin{array}{c}\text { S Real-time viewing of teaching } \\
\text { event by supervisor } \\
\text { S Feedback can be given } \\
\text { immediately during or after } \\
\text { lesson } \\
\text { L Supervisor can only view } 1 \\
\text { teacher teaching at a time }\end{array}$ \\
\hline Asynchronous & $\begin{array}{l}\mathbf{S} \text { Replay and pausing allows for } \\
\text { reflection by PST } \\
\mathbf{S} \text { Internet bandwidth not required } \\
\mathbf{S} \text { Helps in post- } \\
\text { conferencing by supervisor } \\
\end{array}$ & $\begin{array}{l}\text { L Recording possible only via paid } \\
\text { third party application } \\
\text { S Recording via software } \\
\text { application affords same strengths } \\
\text { as pocket camcorder } \\
\end{array}$ & $\begin{array}{c}\text { Not applicable (on-site visit is for } \\
\text { synchronous viewing }\end{array}$ \\
\hline Connectivity & $\begin{array}{l}\text { S Does not rely on internet } \\
\text { connectivity }\end{array}$ & $\begin{array}{c}\text { L Busy Internet or poor } \\
\text { broadband will degrade webcast } \\
\text { quality } \\
\end{array}$ & $\begin{array}{l}\text { S Does not rely on internet } \\
\text { connectivity }\end{array}$ \\
\hline Other & $\begin{array}{c}\text { S Easiest to use of the } 3 \\
\text { technologies trialed } \\
\text { L Did not have as many } \\
\text { functionalities as Adobe Connect }\end{array}$ & $\begin{array}{c}\text { L Web conferencing applications } \\
\text { need more technical knowledge } \\
\text { than Pocket camcorder } \\
\text { S Many functionalities in Adobe } \\
\text { Connect e.g. Chat, polling } \\
\text { whiteboard }\end{array}$ & $\begin{array}{l}\text { S Face-to-face interpersonal } \\
\text { communication with PST and } \\
\text { supervising teacher } \\
\text { S Presence helps to strengthen } \\
\text { networks and partnerships } \\
\text { L Does not have video record of } \\
\text { PST teaching for post viewing or } \\
\text { discussion } \\
\end{array}$ \\
\hline
\end{tabular}

( $\mathbf{S}=$ Strength and $\mathbf{L}=$ Limitation $)$

Internet connectivity and depend on the choice of the camera and microphone. However comparing with pocket camcorders, web conferencing tools require more computer skills to operate. Adobe Connect is highly recommended should the university already have a subscription as its variety of functionalities and quality video transmission made it most applicable for our purpose. Skype would be the second option if subscription cost is a concern and/or ease of use is the most important consideration.

\subsection{What is the Potential of these Technologies for Professional Experience Pedagogy and Beyond?}

The project has supported findings of other projects cited in the literature on the benefits of conferencing such as not having to commute, non-obtrusive observation, PST improving computer literacy and using recordings to help teach other PSTs. It established that technologies can be used to effectively deliver data from the field (the classroom) to base (the university) synchronously and asynchronously and that PSTs can, under some circumstances, be effectively supervised from a distance using technologies.

The trials indicated that both students and staff may benefit from prior awareness of the expectations of the technology and operational training so as to maximize its usage. A further consideration is that of the design of future classrooms, and appropriate desktop access in universities, to multiple camera classrooms in which the various positions of a class might be accessed via remotely controlled cameras. Audio capability might be a further design feature in these environments. In tandem with such developments, facilities in universities might well be used to train pre-service teachers prior to practice teaching, in order to neutralize distraction. From an academic perspective, web conferencing can become fully integrated into teacher education courses. However, work will need to be done to convince all stakeholders, especially academics and the academy that the experience afforded by the technology is not only a worthwhile complement for face-to-face visits but also provides a wealth of opportunities for reflection and the generation of new awareness and possibilities in their own dimension of the practice teaching.

\section{Acknowledgements}

This project was funded by the Department for Education and Early Childhood Development (DEECD), Victoria, Australia.

\section{REFERENCES}

[1] Kent AM. Powerful Preparation of Preservice Teachers using Interactive Video Conferencing. Journal of Literacy and Technology. 2007;8(2):41-58. 
[2] Lehman JD, Richardson J. Assessing the Use of Video Conferencing for Linking Teacher Preparation Programs with K-12 Schools. AECT Conference2007.

[3] Pickering LE, Walsh EJ. Using Videoconferencing Technology to Enhance Classroom Observation Methodology for the Instruction of Preservice Early Childhood Professionals. Journal of Digital Learning in Teacher Education. 2011;27(3):99-108.

[4] Rock ML, Gregg M, Thead BK, Acker SE, Gable RA, Zigmond NP. Can You Hear Me Now? Evaluation of an Online Wireless Technology to Provide Real-Time Feedback to Special Education Teachers-In-Training. Teacher Education and Special Education. 2011;32(1):64-82.

[5] Scheeler MC, Lee DL. Using technology to deliver immediate corrective feedback to preservice teachers. Journal of Behavioral Education. 2002;11:231-41.

[6] Bolton M. Fly on the Wall: Using Teleconferencing to
Supervise Student Teacher Performance. Journal of Open, Flexible, and Distance Learning. 2010;14(1):62-76.

[7] Ardley J. Unanticipated Findings: Gains by Cooperating Teachers via Video-Mediated Conferencing. Journal of computing in teacher education. 2009;25(3):81-6.

[8] Scheeler MC, Ruhl KL, McAfee JK. Providing Performance Feedback to Teachers: A Review. Teacher Education and Special Education. 2011;27(4):396-407.

[9] Capizzi AM, Wehby JH, Sandmel KN. Enhancing Mentoring of Teacher Candidates Through Consultative Feedback of Instructional Delivery. Teacher Education and Special Education. 2010;33(3):191-212.

[10] Sewall M. Transforming Supervision: Using Video Elicitation to Support Preservice Teacher-Directed Reflective Coversations. Issues in Teacher Education. 2009;18(2):11-30.

[11] Richards JC, Farrell TSC. Practice Teaching: A reflective approach. New York: Cambridge University Press; 2011. 